\title{
Enhancement of antitumor activity by using 5-ALA-mediated sonodynamic therapy to induce apoptosis in malignant gliomas: significance of high-intensity focused ultrasound on 5-ALA-SDT in a mouse glioma model
}

\author{
Satoshi Suehiro, MD, ${ }^{1}$ Takanori Ohnishi, MD, PhD, ${ }^{4}$ Daisuke Yamashita, MD, PhD, ${ }^{1}$ \\ Shohei Kohno, MD, PhD, ${ }^{1}$ Akihiro Inoue, MD, PhD, ${ }^{1}$ Masahiro Nishikawa, MD, ${ }^{1}$ \\ Shiro Ohue, MD, PhD, ${ }^{2}$ Junya Tanaka, MD, PhD, ${ }^{3}$ and Takeharu Kunieda, MD, PhD ${ }^{1}$
}

Departments of ${ }^{1}$ Neurosurgery and ${ }^{3}$ Molecular and Cellular Physiology, Ehime University Graduate School of Medicine, Toon; ${ }^{2}$ Department of Neurosurgery, Ehime Prefectural Central Hospital, Matsuyama; and ${ }^{4}$ Department of Neurosurgery, Washoukai Sadamoto Hospital, Matsuyama, Ehime, Japan

OBJECTIVE High invasiveness of malignant gliomas frequently causes early local recurrence of the tumor, resulting in extremely poor outcome. To control such recurrence, novel therapies targeted toward infiltrating glioma cells around the tumor border are required. Here, the authors investigated the antitumor activity of sonodynamic therapy (SDT) combined with a sonosensitizer, 5-aminolevulinic acid (5-ALA), on malignant gliomas to explore the possibility for clinical use of 5-ALA-mediated SDT (5-ALA-SDT).

METHODS In vitro cytotoxicity of 5-ALA-SDT was evaluated in U87 and U251 glioma cells and in U2510ct-3/4 glioma stemlike cells. Treatment-related apoptosis was analyzed using flow cytometry and TUNEL staining. Intracellular reactive oxygen species (ROS) were measured and the role of ROS in treatment-related cytotoxicity was examined by analysis of the effect of pretreatment with the radical scavenger edaravone. Effects of 5-ALA-SDT with high-intensity focused ultrasound (HIFU) on tumor growth, survival of glioma-transplanted mice, and histological features of the mouse brains were investigated.

RESULTS The 5-ALA-SDT inhibited cell growth and changed cell morphology, inducing cell shrinkage, vacuolization, and swelling. Flow cytometric analysis and TUNEL staining indicated that 5-ALA-SDT induced apoptotic cell death in all gliomas. The 5-ALA-SDT generated significantly higher ROS than in the control group, and inhibition of ROS generation by edaravone completely eliminated the cytotoxic effects of 5-ALA-SDT. In the in vivo study, 5-ALA-SDT with HIFU greatly prolonged survival of the tumor-bearing mice compared with that of the control group $(p<0.05)$. Histologically, 5-ALA-SDT produced mainly necrosis of the tumor tissue in the focus area and induced apoptosis of the tumor cells in the perifocus area around the target of the HIFU-irradiated field. The proliferative activity of the entire tumor was markedly decreased. Normal brain tissues around the ultrasonic irradiation field of HIFU remained intact.

CONCLUSIONS The 5-ALA-SDT was cytotoxic toward malignant gliomas. Generation of ROS by the SDT was thought to promote apoptosis of glioma cells. The 5-ALA-SDT with HIFU induced tumor necrosis in the focus area and apoptosis in the perifocus area of the HIFU-irradiated field, whereas the surrounding brain tissue remained normal, resulting in longer survival of the HIFU-treated mice compared with that of untreated mice. These results suggest that 5-ALA-SDT with HIFU may present a less invasive and tumor-specific therapy, not only for a tumor mass but also for infiltrating tumor cells in malignant gliomas.

https://thejns.org/doi/abs/10.3171/2017.6.JNS162398

KEY WORDS malignant gliomas; 5-aminolevulinic acid; sonodynamic therapy; high-intensity focused ultrasound; apoptosis; oncology

ABBREVIATIONS DCFH-DA = dichlorodihydrofluorescein diacetate; DPBS = Dulbecco phosphate-buffered saline; FBS = fetal bovine serum; FUS = focused ultrasound; GSL = glioma stemlike; HIFU = high-intensity focused ultrasound; IP = intraperitoneal; NSC = neural stem cell; PDT = photodynamic therapy; PFA = paraformaldehyde; PpIX = protoporphyrin IX; ROS = reactive oxygen species; SDT = sonodynamic therapy; TBS = Tris-buffered saline; US = ultrasound; 5-ALA = 5-aminolevulinic acid; 5-ALASDT = 5-ALA-mediated SDT.

SUBMITTED September 16, 2016. ACCEPTED June 5, 2017.

INCLUDE WHEN CITING Published online January 19, 2018; DOI: 10.3171/2017.6.JNS162398. 
$\mathrm{M}$ ALIGNANT glioma, particularly glioblastoma, is the most common and aggressive primary brain tumor, with a median survival time of less than 15 months after maximum resection of the tumor followed by the current standard radiochemotherapy. ${ }^{19}$ The extremely poor outcome of malignant glioma is largely due to its highly invasive nature, which frequently causes early recurrence of the tumor, particularly around the resection cavity, resulting in local recurrence. Therefore, a novel therapy capable of controlling not only unresectable tumors but also infiltrating tumor cells around the tumor border is urgently required.

Recently, intraoperative photodynamic therapy (PDT) with talaporfin sodium was introduced to locally control malignant gliomas, and has shown the possibility of preferential inhibition of tumor growth. ${ }^{12}$ Although PDT is expected to be a useful tool in the control of local recurrence of malignant glioma, it has the disadvantage of low penetration of the laser light into tissues. On the other hand, sonodynamic therapy (SDT), in which a sonosensitizer is combined with ultrasound (US) that can penetrate deeply into tissue, has been shown to be effective for the treatment of various cancers. ${ }^{7,10}$ In malignant glioma, 5-aminolevulinic acid (5-ALA) has been widely used for intraoperative tumor visualization to distinguish the tumor border and detect the existence of residual tumors. ${ }^{18}$ In addition, 5-ALA has been found to be a potent sensitizer for SDT in various cancers..$^{15}$ To date, many in vitro studies using SDT combined with 5-ALA as a sonosensitizer in gliomas have been reported, but there have only been a few in vivo studies of SDT in animal models. ${ }^{8,13,14}$ The previous in vivo studies demonstrated a tumor-suppressive effect of SDT with a sonosensitizer; however, only a few of those studies referred to effects of SDT on the survival of tumor-bearing animals. In addition, because the US used in those studies was not high-intensity focused ultrasound (HIFU), serious injury to normal brain tissues could occur in the entire area irradiated by the high-power US. Recent progress of MR-guided focused ultrasound (MRgFUS) for the brain has enabled effective treatment of essential tremor, Parkinson disease, and chronic neuropathic pain in clinical studies. ${ }^{4,20}$ The innovation of therapeutic FUS prompted us to apply SDT with HIFU to brain tumors as a tumor-specific and less-invasive therapy without craniotomy.

In the present study, we examined the antitumor effects of 5-ALA-mediated SDT (5-ALA-SDT) in malignant gliomas in vitro and in vivo. We demonstrated that 5-ALA-SDT showed effective cytotoxicity against malignant gliomas through the induction of apoptosis. In addition, 5-ALA-SDT performed using HIFU markedly inhibited in vivo tumor growth in mice by not only inducing necrosis in the focus area but also inducing apoptosis in the glioma cells in the perifocus area around the target of HIFU, resulting in longer survival of tumor-bearing mice than of those receiving HIFU alone or no treatment.

\section{Methods \\ Ethics Statement}

The mouse experiments were performed according to protocols approved by the animal care and use committees of Ehime University. These protocols are in accordance with the standards detailed in the National Research Council's Guide for the Care and Use of Laboratory Animals. ${ }^{3}$ The surgery and experimental procedures were performed after animals were anesthetized with intraperitoneal (IP) medetomidine $(0.75 \mathrm{mg} / \mathrm{kg})$, midazolam $(4 \mathrm{mg} / \mathrm{kg})$, and butorphanol tartrate $(5 \mathrm{mg} / \mathrm{kg})$, and utmost efforts were made to minimize animal suffering.

\section{Cells and Cell Culture}

The human malignant glioma cell lines U87 and U251 were obtained by purchasing the U87MG (HTB14) cell line from the American Type Culture Collection, and by transfer of the U251 cell line from the Hyogo College of Medicine (Hyogo, Japan). The U251 ${ }^{\text {Oct-3/4 }}$ glioma stemlike (GSL) cells were obtained by transfection of the Oct-3/4 expression plasmid into U251 cells as described previously. ${ }^{6,9,22}$ Human normal neural stem cells (NSCs; ReNcell VM) were purchased from Merck Millipore and maintained according to the supplier's instructions. The glioma cells were cultured in DMEM (Wako) supplemented with $10 \%$ heat-incubated fetal bovine serum (FBS; Thermo Scientific), $100 \mathrm{U} / \mathrm{ml}$ penicillin $\mathrm{G}$, and $100 \mu \mathrm{g} / \mathrm{ml}$ streptomycin, in an incubator with $5 \% \mathrm{CO}_{2}$ and $100 \%$ humidity at $37^{\circ} \mathrm{C}$. Cells in the exponential phase of growth were used in all of the experiments.

\section{In Vitro SDT Combined With 5-ALA}

Cells were harvested by trypsinization, centrifuged, and resuspended in DMEM containing 10\% FBS. An equal number of cells was then seeded into 16 wells of a 96-well plate (FALCON353072; BD) so that neighboring wells were free of cells. Each well contained $100 \mu \mathrm{l}$ of cell suspension and approximately $4 \times 10^{4}$ cells $/ \mathrm{ml}$, and the plates were incubated at $37^{\circ} \mathrm{C}$ in a $5 \% \mathrm{CO}_{2}$ atmosphere for 24 hours. The cells were washed with $\mathrm{Ca}^{2+}, \mathrm{Mg}^{2+}$-free Dulbecco phosphate-buffered saline (DPBS[-]) and then incubated with or without $1 \mathrm{mM}$ 5-ALA (Cosmo BioCo., Ltd.) for 4 hours in DMEM with 10\% FBS. The culture plates were then divided evenly into 4 experimental groups: 2 with no US treatment (control and 5-ALA alone) and 2 with US treatment (US alone and 5-ALA-SDT). The US irradiation was applied to cells in the dark. To irradiate glioma cells in culture with US, the culture plates were placed above a probe, and the gap between the culture plates and the probe was filled with cooled echo gel (ITO Physiotherapy \& Rehabilitation). We used a 3-MHz US generator (UST-770; ITO Physiotherapy \& Rehabilitation) with an FUS transducer that was a single, 35-mm-diameter circular disc. The US conditions of $2 \mathrm{~W} / \mathrm{cm}^{2}$ and $20 \%$ duty cycle for 3 minutes were used. To analyze the effects of US or 5-ALA-SDT on cell morphology and proliferation, the cells were reincubated after the treatment for up to 24 hours in the dark.

\section{Cytotoxicity Assay}

Cytotoxicity (cell growth inhibition) induced by US alone or by 5-ALA-SDT was analyzed using the colorimetric assay in the Cell Counting Kit-8 (Dojindo). ${ }^{23}$ 
Briefly, an appropriate amount of the Cell Counting Kit-8 solution was added to the culture medium, followed by incubation at $37^{\circ} \mathrm{C}$ for 90 minutes. The reaction was then terminated by adding $1 \mathrm{w} / \mathrm{v} \%$ sodium dodecyl sulfate to the medium, and the absorbance was measured at 450 $\mathrm{nm}$ (reference wavelength $600 \mathrm{~nm}$ ) by using a microplate reader (iMark; BioRad) in accordance with the manufacturer's instructions.

\section{Cell Morphology After SDT}

Cells were treated with US alone or with 5-ALA-SDT. The US condition was the same as that used in the in vitro SDT study described above. The cells were then incubated in DMEM with $10 \%$ FBS for 12 hours. Cell morphology was then observed under a phase-contrast microscope (Floid cell imaging station; Life Technologies).

\section{Flow Cytometric Analysis}

Glioma cells were seeded into 4 wells of a 48 -well plate. Each well contained approximately $10^{5}$ cells $/ \mathrm{ml}$ in $500 \mu \mathrm{l}$ of cell suspension. The plates were incubated at $37^{\circ} \mathrm{C}$ in a $5 \% \mathrm{CO}_{2}$ atmosphere for 24 hours. After washing with DPBS(-), they were incubated with $1 \mathrm{mM} 5$-ALA in DMEM with $10 \%$ FBS for 4 hours. The SDT was performed using the same US conditions as described above. After 12 hours, the percentage of apoptotic cells induced by the SDT treatment was analyzed using the Gallios flow cytometer (Beckman Coulter) and FlowJo software (FlowJo) with the Annexin V-Cy5 apoptosis detection kit (BioVision) according to the manufacturer's instructions.

\section{TUNEL Staining}

The glioma cells were seeded onto 8-well glass slides (154941; Nunc) coated with poly-D-lysine (Sigma-Aldrich). Each well contained $200 \mu \mathrm{l}$ of cell suspension and approximately $1.5 \times 10^{4}$ cells $/ \mathrm{ml}$. The slides were incubated at $37^{\circ} \mathrm{C}$ in a $5 \% \mathrm{CO}_{2}$ atmosphere for 24 hours. After washing with DPBS(-), they were then incubated with 1 mM 5-ALA in DMEM with $10 \%$ FBS for 4 hours. The cells were then immersed in fresh DMEM with $10 \%$ FBS. The slides were divided evenly into 2 treatment groups: US alone ( $2 \mathrm{~W} / \mathrm{cm}^{2}$ and $20 \%$ duty cycle for 3 minutes) and 5-ALA + US. After 12 hours, the medium was discarded, and the slides were dried and fixed in $4 \%$ paraformaldehyde (PFA) for 30 minutes. The slides were then incubated for 2 minutes on ice in the presence of $0.2 \%$ Triton X-100. After washing with DPBS(-), TMR red (In Situ Cell Death Detection Kit; Roche Life Science) was added to the well and incubated at $37^{\circ} \mathrm{C}$ for 60 minutes. At 30 minutes after incubation, Hoechst 33342 (Life Technologies) was added to the well. The slide was sealed with a coverslip, and positive fluorescence showing DNA fragmentation was observed under a fluorescence microscope (BZ-9000; Keyence), in accordance with the manufacturer's instructions.

\section{Measurement of Intracellular Reactive Oxygen Species}

The U87 and U251 glioma cells were seeded into 4 wells of a 48-well plate. Each well contained $500 \mu \mathrm{l}$ of cell suspension and approximately $10^{5}$ cells $/ \mathrm{ml}$. The plate was incubated at $37^{\circ} \mathrm{C}$ in a $5 \% \mathrm{CO}_{2}$ atmosphere for 24 hours. After washing with DPBS(-), the cells were incubated with $1 \mathrm{mM}$ 5-ALA in DMEM with $10 \%$ FBS for 4 hours. Then, the cells were washed twice with DPBS(-) and incubated with $400 \mu \mathrm{M}$ dichlorodihydrofluorescein diacetate (DCFH-DA; OxySelect Intracellular ROS Assay Kit [Green Fluorescence]; Cell Biolabs, Inc.) for 5 minutes. After washing with DPBS(-), the cells were treated with US $\left(2 \mathrm{~W} / \mathrm{cm}^{2}\right.$ and $20 \%$ duty cycle for $3 \mathrm{~min}-$ utes). After treatment, the medium was removed from all wells and discarded. The cells were gently washed twice with DPBS(-). The medium was removed from each well and the cells were incubated with cell lysis buffer for 10 minutes. The mixture was then transferred to a 96-well black plate (FALCON353219; BD) for fluorescence measurement. Fluorescence intensity was measured using the fluorescence microplate reader (FlexStation 3; Molecular Devices) at wavelengths of $480 \mathrm{~nm}$ excitation/530 nm emission.

\section{Effects of Inhibition of Reactive Oxygen Species Generation on SDT-Induced Cytotoxicity}

To examine the significance of reactive oxygen species (ROS) for the cytotoxicity of SDT, the effects of the radical scavenger edaravone (Tanabe-Mitsubishi Co., Ltd.) on the cytotoxicity induced by SDT were analyzed using the Cell Counting Kit-8. ${ }^{23}$ An equal number of cells were seeded into 20 wells of a 96-well plate (FALCON353072) so that neighboring wells were free of cells. Each well contained $100 \mu \mathrm{l}$ of cell suspension and approximately $4 \times$ $10^{4} \mathrm{cells} / \mathrm{ml}$, and the plates were incubated at $37^{\circ} \mathrm{C}$ in a $5 \%$ $\mathrm{CO}_{2}$ atmosphere for 24 hours. The cells were washed with DPBS(-) and were then incubated with or without $1 \mathrm{mM}$ 5-ALA for 4 hours in DMEM with 10\% FBS. The culture plates were then divided evenly into 5 experimental groups: 3 for no US treatment (control, edaravone alone, and edaravone + 5-ALA) and 2 for US treatment (US + edaravone and US + 5-ALA + edaravone). The cells were washed and $100 \mu \mathrm{l}$ of DMEM with $10 \%$ FBS with or without $30 \mu \mathrm{g}$ of edaravone was added just prior to SDT. US was applied to cells in the dark. Cytotoxicity was measured by the colorimetric assay using the Cell Counting Kit- 8 as described above.

\section{In Vivo Tumor Model}

Immunodeficient mice were obtained from CLEA Japan, Inc. During the experimental period, the mice were kept in a cage and housed in a temperature- and humiditycontrolled aseptic room provided with a light/dark cycle system. Either U87 glioma cells or U251 ${ }^{\text {Oct-3/4 }}$ GSL cells $\left(10^{5}\right)$ were suspended in $3 \mu \mathrm{l}$ of the culture medium and injected into the brains of 6- to 8-week-old, female, specific pathogen-free, nu/nu BALB/c mice (weight $20 \pm 2 \mathrm{~g}$ [mean $\pm \mathrm{SD}]$ ) by using a stereotactic apparatus (Narishige). Before placing the mice in the stereotactic apparatus, the animals were anesthetized with IP medetomidine $(0.75 \mathrm{mg} /$ $\mathrm{kg})$, midazolam $(4 \mathrm{mg} / \mathrm{kg})$, and butorphanol tartrate $(5 \mathrm{mg} /$ $\mathrm{kg}$ ). The stereotactic coordinates of the injection site were as follows: $1 \mathrm{~mm}$ forward from the coronal suture, $2 \mathrm{~mm}$ lateral to the sagittal suture, and $3 \mathrm{~mm}$ deep. Preliminary 
MRI of the mouse brain was performed to confirm the size and location of a generated tumor just before performing SDT.

\section{In Vivo SDT With HIFU}

The 5-ALA was administered to the mice at a dose of $100 \mathrm{mg} / \mathrm{kg}$ via a transgastric route. Four hours after administration of 5-ALA, tumor-bearing mice were anesthetized with IP medetomidine $(0.75 \mathrm{mg} / \mathrm{kg})$, midazolam $(4 \mathrm{mg} / \mathrm{kg})$, and butorphanol tartrate $(5 \mathrm{mg} / \mathrm{kg})$, and an acoustically transparent gel was applied on the head skin so that the transplanted tumor was located under the gel. A HIFU transducer with a diameter of $20 \mathrm{~mm}$ was horizontally attached to the surface of skin over the intracranial tumor. We focused the US irradiation of HIFU on the center of the growing tumor in the mouse brain. To carry out such a focused irradiation, the position of the center of the tumor was assessed by obtaining a tumor image with MRI. Because the measured position of the center of the tumor did not significantly differ from the injection site in most tumors, the HIFU transducer was set on the injection site. The tumor injection site was measured with the stereotactic apparatus and the transducer was fixed to the injection site by applying a custom-made attachment (Narishige).

Ultrasonic irradiation was performed by placing 12 $\mathrm{mm}$ of degassed gel between the transducer and the skin. The frequency and sound strength of the US (Sonitron GTS) were $2.2 \mathrm{MHz}$ and $0.5 \mathrm{~kW} / \mathrm{cm}^{2}$, respectively. One US irradiation was performed at $100 \%$ duty cycle for 5 minutes. Mouse brains received US irradiation with the same modes once a week for 3 weeks, to control the rapid growth of the residual tumor and reduce the tumor volume as much as possible. All SDT experiments were conducted at $20^{\circ} \mathrm{C}$ under a dim light condition. The experimental study consisted of 4 groups: 5-ALA-SDT with HIFU, 5-ALA alone, HIFU alone, and no treatment (control). Tumor-transplanted mice were randomly assigned $(n=5$ for each group). During the survival study, we monitored the condition of the animals every day. There were no unexpected deaths. We humanely killed the mice when they began to show abnormal signs or behaviors, including difficulty in food and water intake, abnormal posture, selfinjurious behavior, or marked weight loss (10\% in a day) for more than 3 consecutive days. The mice were killed by anesthesia with an overdose of barbiturate, and the death was confirmed by verification of cessation of breathing followed by cervical dislocation. These experiments were conducted under a uniform sonication condition that was based on the results of preliminary studies in which the most efficient condition for in vivo SDT was determined. All experiments were conducted at $20^{\circ} \mathrm{C}$ under a dim light condition. In addition, the survival time of the mice in each group was evaluated with reference to the MRI findings.

\section{Histopathological and Immunohistochemical Investigations}

The mice whose brain tumors were treated with SDT were anesthetized and fixed by perfusion of $4 \%$ PFA, and the brains were removed. The brain samples were fixed again in 4\% PFA for 12 hours and were embedded in liquid paraffin. Thin sections of 4- $\mu \mathrm{m}$ thickness were stained with $\mathrm{H} \& \mathrm{E}$. For immunohistochemistry, tissue sections were deparaffinized and immersed in Target Retrieval Solution (Dako). The sections were then heated 3 times in a microwave oven for 5 minutes each time, and were washed in Tris-buffered saline (TBS). Endogenous peroxidase was blocked with $3 \% \mathrm{H}_{2} \mathrm{O}_{2}$ for 15 minutes. After washing in TBS, the sections were incubated with the following primary antibodies at $4{ }^{\circ} \mathrm{C}$ overnight: rabbit monoclonal anticaspase-3, cleaved (\#9664, 1:100; Cell Signaling Technology) and mouse monoclonal anti-Ki-67 (M7240, 1:200; Dako). The sections were then washed 3 times in TBS and incubated with peroxidase-labeled anti-rabbit or anti-mouse antibody (Histofine Simplestain Max PO; Nichirei) for 30 minutes at room temperature. Peroxidase activity was detected with diaminobenzidine (Histofine Simplestain DAB; Nichirei). The sections were counterstained with hematoxylin and dehydrated.

\section{Statistical Analysis}

An IBM SPSS Statistics software program was used for statistical analysis. The average \pm SD value for each group was also tabulated, and these values were compared using 1-way ANOVA and Tukey's post hoc test. Survival data were compared using the Kaplan-Meier method with a logrank test. A $p$ value of $<0.05$ was considered significant.

\section{Results}

\section{Effects of 5-ALA-SDT on the Growth of Glioma Cells}

We examined the antitumor effects of US alone and of 5-ALA-SDT by analyzing their growth inhibition of 2 glioma cell lines and GSL cells along with normal NSCs. Cell growth inhibition was analyzed by a colorimetric assay using the Cell Counting Kit-8 (Fig. 1). Treatment with US alone was cytotoxic toward U87 glioma cells and U251 ${ }^{\text {oct-3/4 }}$ GSL cells, but did not have a significant antitumor effect against U251 glioma cells. The group treated with 5-ALA-SDT showed a much stronger inhibitory effect on the growth of all glioma cells and U251 $1^{\text {Oct-3/4 }} \mathrm{GSL}$ cells than US alone. Administration of 5-ALA alone did not have antitumor effects toward any glioma cells and normal NSCs. In addition, neither US alone nor 5-ALASDT had cytotoxic effects on normal NSCs.

\section{Cell Morphological Changes Induced by SDT}

Phase-contrast microscopic analysis of the cells at 12 hours after treatment with US alone indicated decreased growth of all of the glioma cells and marked cell shrinkage compared with the control. In addition to induction of cell shrinkage, 5-ALA-SDT also induced vacuolization, and disappearance of cellular processes with some blebbing and swelling of the glioma cells. The 5-ALA alone had no effect on the morphology of the glioma cells (Fig. 2).

\section{Flow Cytometric Analysis of Cell Death}

We evaluated the mode of cell death after SDT treatment of glioma cells by using flow cytometry with the Annexin V-Cy5 apoptosis detection kit. US alone increased 

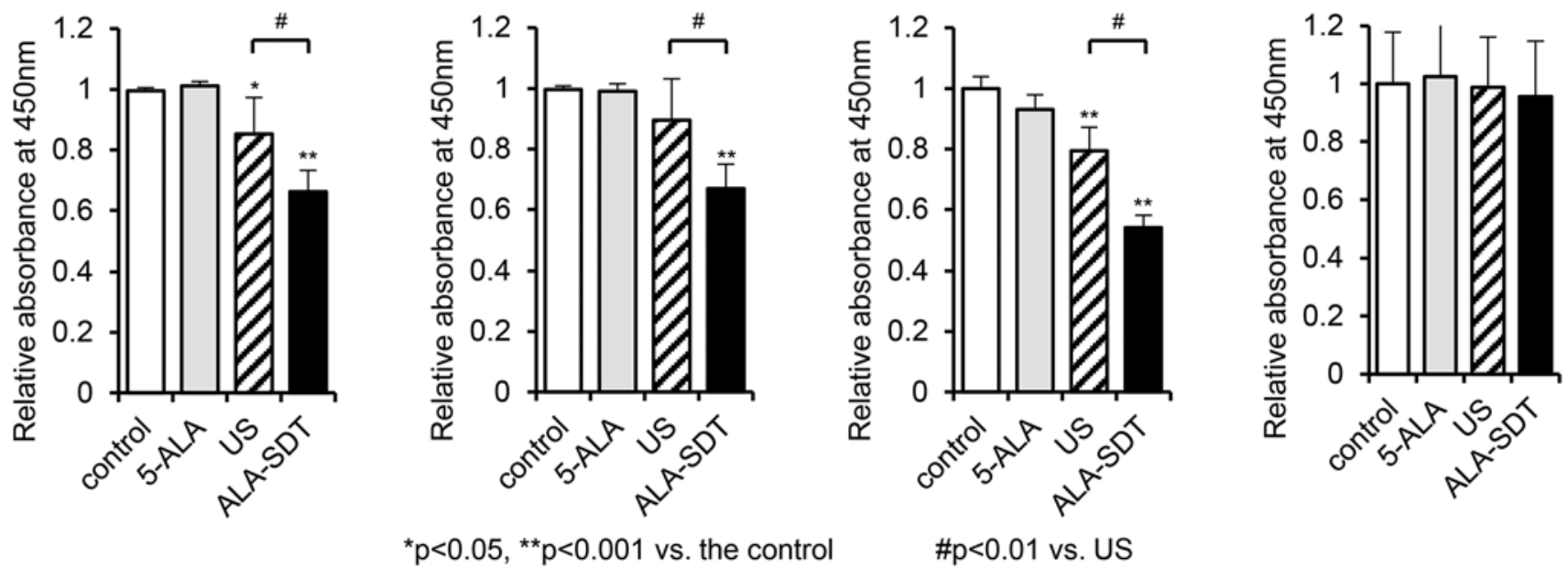

FIG. 1. Bar graphs showing cytotoxicity of 5-ALA-SDT in glioma cells. Effects of SDT performed using US combined with 5-ALA on the growth of the indicated glioma cells, as evaluated using a colorimetric assay. Treatment with US alone showed significant growth-inhibitory effects against U87 and U2510ct-3/4 cells. The 5-ALA-SDT showed a significantly stronger cytotoxicity toward all glioma cells than either the control $(p<0.001)$ or US alone $(p<0.01)$. The 5 -ALA alone showed no cytotoxicity toward any glioma cell line. Values are expressed as the mean \pm SD of experiments conducted at least in triplicate.

the apoptotic cell population in all glioma cells, including GSL cells to various degrees. The 5-ALA-SDT induced a much higher increase in the apoptotic population in all glioma cells than US alone (Fig. 3).

\section{TUNEL Staining}

The results of TUNEL staining of DNA fragmentation, which provides histochemical verification of apoptosis, were then assessed. Only a few fluorescence-positive cells were observed following US treatment alone. In contrast, many fluorescence-positive cells were observed following 5-ALASDT, and this increase in fluorescent cells after SDT compared with US treatment alone was seen not only in apoptotic glioma cells but also in apoptotic GSL cells (Fig. 4).
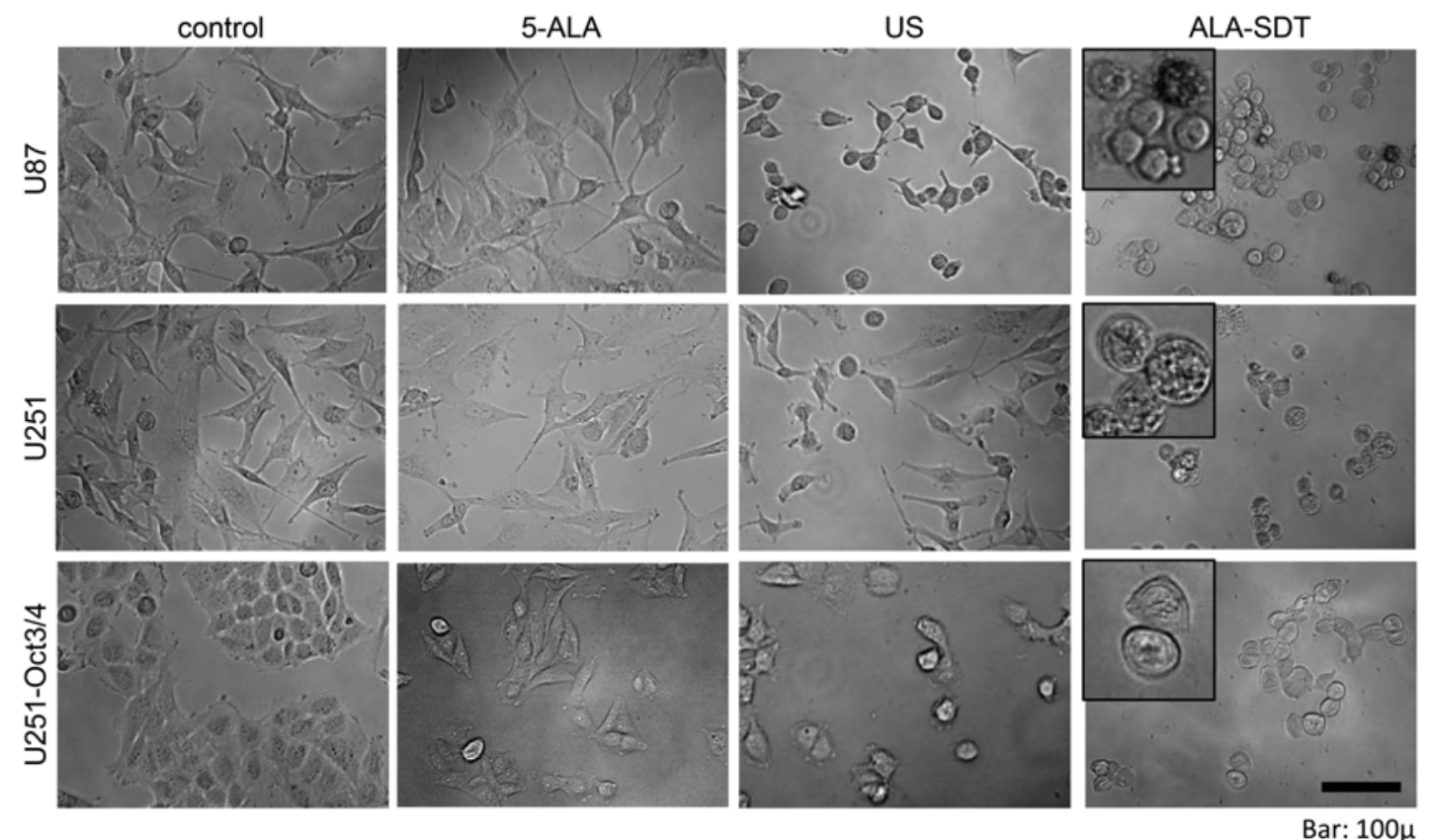

FIG. 2. Use of 5-ALA-SDT induces morphological changes in glioma cells. The effect of US alone or with 5-ALA-SDT (US + 5-ALA) on the morphology of the indicated glioma cells was analyzed using phase-contrast microscopy. Both 5-ALA-SDT and US alone decreased the cell density and induced marked cell shrinkage in all glioma cells. Use of 5-ALA alone did not have any effect on the morphology of the glioma cells. Note the intracellular vacuolization, shortening of cellular processes, and swelling in all glioma cells promoted by 5-ALA-SDT. The insets show cells at higher magnification. 

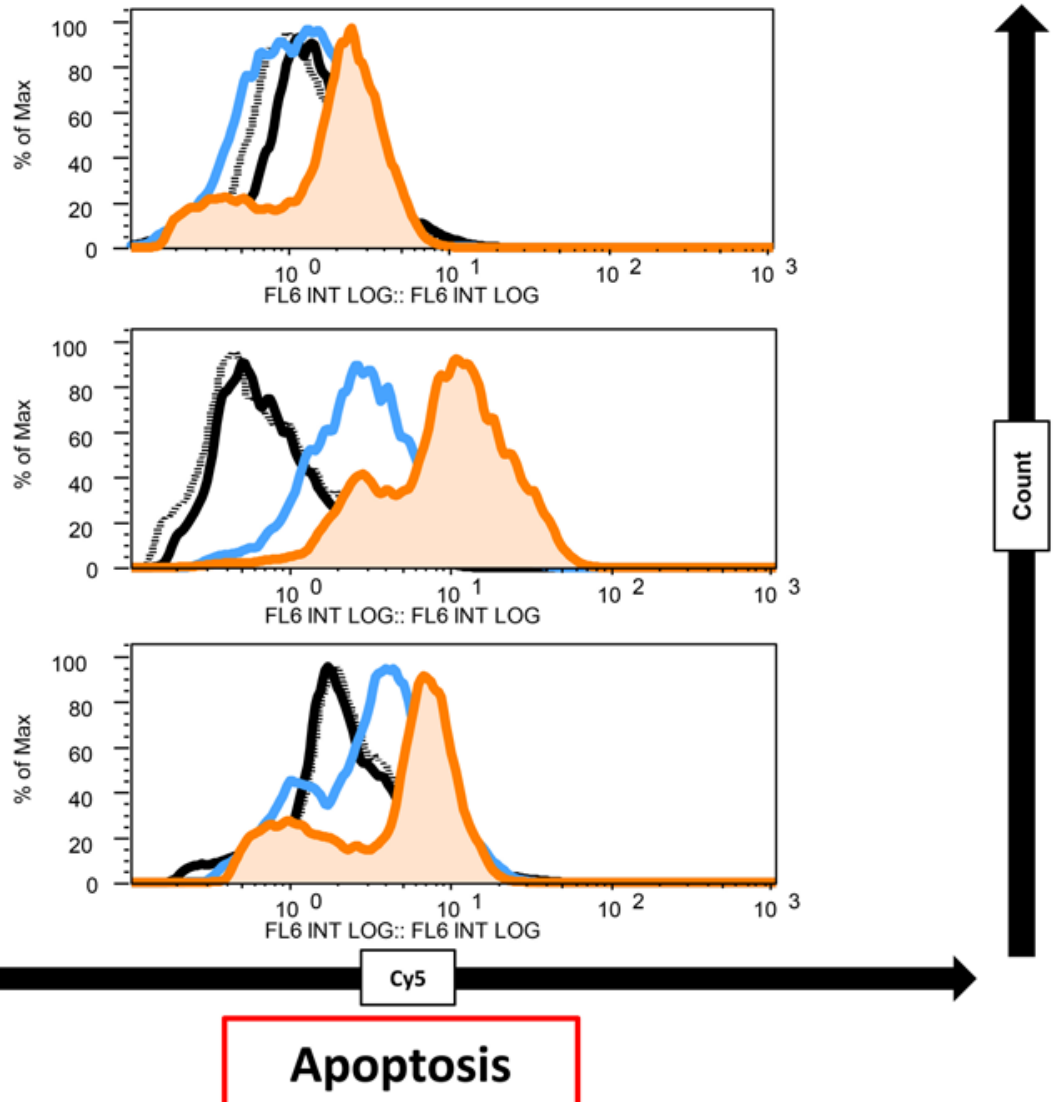

\section{control}

ALA

US

ALA-SDT

FIG. 3. Flow cytometric analysis of glioma cells treated with 5-ALA-SDT. Flow cytometric analysis of the indicated cells following 5-ALA-SDT or treatment with US alone was performed using the Annexin V-Cy5 apoptosis detection kit. Although US alone induced early apoptosis in U251 glioma cells and U251 ${ }^{\text {oct-3/4 }} \mathrm{GSL}$ cells, 5-ALA-SDT resulted in a much greater increase in the apoptotic cell population in all cell types than US alone.

\section{Quantitative Analysis of ROS in SDT}

The amount of ROS generated by SDT was evaluated by measuring the fluorescence intensity of DCFH-DA within the glioma cells. For this purpose, only the 2 glioma cell lines, U87 and U251, were assayed. The U251 Oct-3/4 cells could not be assayed using this ROS assay kit because these cells were cotransfected with an enhanced green fluorescent protein expression vector. Even US alone generated significantly higher amounts of ROS than the control in U251 cells. Treatment with 5-ALA-SDT significantly generated much more ROS than the control in both U87 and U251 cells. In addition, 5-ALA-SDT produced more highly ROS than US alone, but there was no significant difference in the generated ROS between the 2 treatment modes (Fig. 5A).

\section{Effect of Inhibition of the Generation of ROS on 5-ALA-SDT-Induced Cytotoxicity}

The significance of ROS as a cause of the cytotoxicity induced by 5-ALA-SDT was analyzed by determination of the effect of inhibition of the generation of ROS by treatment of the cells with edaravone. Administration of edaravone completely eliminated the cytotoxic effects of not only 5-ALA-SDT but also US alone (Fig. 5B). These results may suggest that the apoptosis that occurred in cells treated with 5-ALA-SDT or with US alone was induced by ROS that was generated by a chemical reaction promoted by US and 5-ALA or US itself.

\section{Histopathological Characteristics of the Tumor Tissue After SDT in Tumor-Bearing Mice}

To analyze the effects of HIFU on the histopathological characteristics of the tumor tissue in the irradiation field in the brains of mice, the field was divided into 2 areas: focused and perifocused. The latter was defined as an area within a $0.5-\mathrm{mm}$ radius around the focused area (see Fig. 6J, illustration of the irradiation field of HIFU). Tumor tissues were stained with $\mathrm{H} \& \mathrm{E}$ and were also immunohistochemically examined for apoptotic cells by using an anticaspase- 3 antibody and for mitotic cells by using an anti-Ki-67 antibody. Transplantation of U251 GSL cells into the brain of nude mice formed a massive tumor, with tumor invasion that had a high cellular density, with many atypical nuclei and mitosis, whose histological characteristics closely resembled those of human glioblastoma (Fig. 6G). Histological examination revealed that 5-ALA-SDT with HIFU induced necrosis of the tumor tissue at the center of the focused area of HIFU ir- 

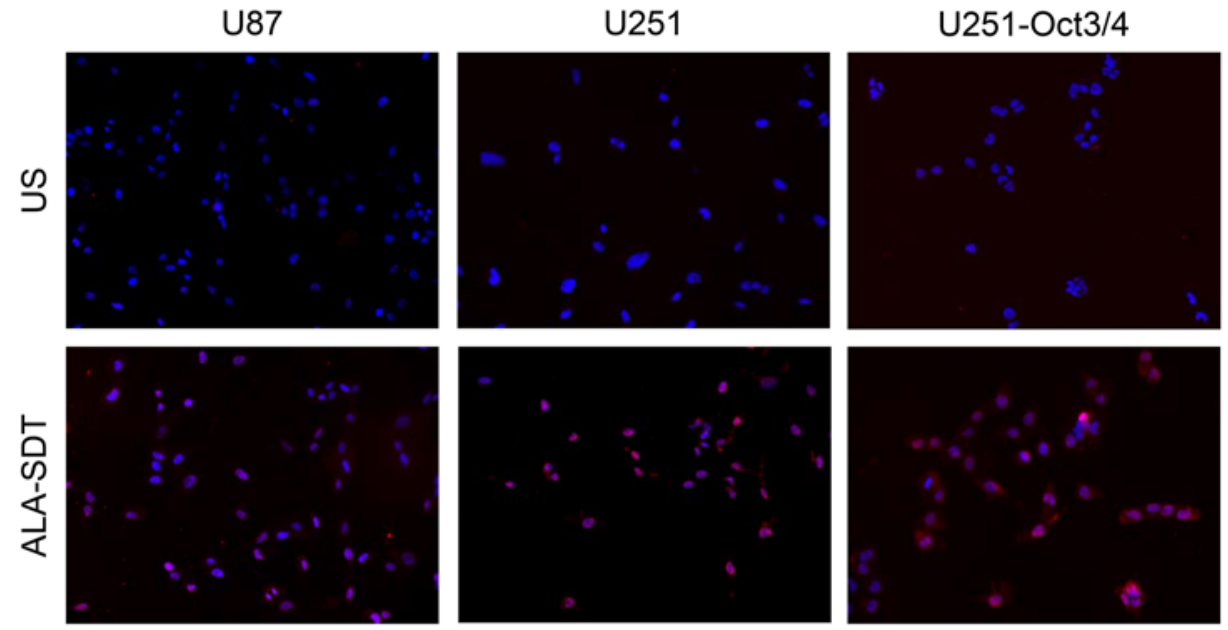

Hoechst / TUNEL

FIG. 4. Photomicrographs showing TUNEL staining of glioma cells treated with or without 5-ALA-SDT. Results of TUNEL staining of glioma and GSL cells treated with US alone (upper row) or 5-ALA-SDT (lower row). The TUNEL-stained apoptotic cells (red) and nuclei counterstained with Hoechst (b/ue) are shown. Fragmentation of DNA, as indicated by positive TUNEL fluorescence, was observed in only a few cells following treatment with US alone, but this was greatly increased in glioma and GSL cells by 5-ALA-SDT.

radiation (Fig. 6A). Some of the remaining tumor cells in the area were positively stained for caspase-3 (Fig. 6B), and a few Ki-67-positive cells were observed (Fig. 6C). In the perifocused area, the number of tumor cells was markedly decreased even in the nonnecrotic region (Fig. 6D), and caspase-3-positive tumor cells were observed to form a dotted pattern (Fig. 6E). Almost no Ki-67-positive tumor cells were observed in the perifocused area (Fig. 6F), showing that cell proliferation as assessed by the number of Ki-67-positive cells was markedly decreased compared with the control (Fig. 6I). On the other hand, HIFU alone induced a slight necrotic change in tumor cells and a few caspase-3-positive tumor cells in the focused area. The brain tissue within the irradiation field of HIFU displayed normal histological structures (Fig. 6K). Compared with the control (untreated) brain, the number of Ki-67-positive cells in the perifocused areas was reduced by HIFU alone to $30.5 \%$, but there were only a few caspase-3-positive tumor cells in perifocused areas (Fig. 7).

\section{Effects of SDT on the Survival of Tumor-Bearing Mice}

We investigated the effects of 5-ALA-SDT with HIFU on the survival of glioma-bearing mice. Postprocedure MRI demonstrated that 1 treatment of 5-ALA-SDT with HIFU partly decreased the tumor mass, which was recognized as a defect area of Gd enhancement on MRI (Fig. 8A). In addition, the rate of increase in size of the remaining tumor at 3 days after 5-ALA-SDT was much lower than that of the control. Three courses of treatment of 5-ALA-SDT with HIFU significantly prolonged the survival of glioma-bearing mice compared with control animals ( $p<0.001$; Fig. 8B). Irradiation using HIFU alone also prolonged mouse survival, but the difference between HIFU alone and control was not statistically significant. The cause of death in mice treated with SDT was related to proliferation of the surviving tumors in both treatment groups (5-ALA-SDT with HIFU and HIFU alone).

\section{Discussion}

\section{Antitumor Effects of SDT Combined With 5-ALA}

In the present study, we demonstrated that SDT combined with a sonosensitizer, 5-ALA, had significantly stronger antitumor effects against human malignant gliomas both in vitro and in vivo than did US alone. To date, it has been reported that US exhibits its antitumor activity not only through a thermal effect but also by the chemical action of ultrasonic irradiation, even at a very low intensity (less than $0.5 \mathrm{~kW} / \mathrm{cm}^{2}$ ). ${ }^{5,24}$ However, our preliminary study revealed that US administered at such a low intensity did not show cytotoxicity against glioma cells (data not shown). In the present study, we found that US alone at an intensity of $2 \mathrm{~W} / \mathrm{cm}^{2}$ did not have an antitumor effect toward U251 glioma cells, although US with the same intensity did induce a cytotoxic response in other glioma and GSL cells. On the other hand, the combination of 5-ALA and US showed significant antitumor effects toward all glioma and GSL cells under US conditions of $2 \mathrm{~W} / \mathrm{cm}^{2}$ and 20\% duty cycle for 3 minutes. These results indicate that US with an intensity of not less than $2 \mathrm{~W} / \mathrm{cm}^{2}$ might be required for effective use of SDT with 5-ALA for malignant gliomas.

\section{Apoptosis Induced by 5-ALA-SDT}

Since US insonation with a high intensity can possibly cause heat or mechanical injury to tumor cells, as well as to normal brain tissues, a combination of sonosensitizers and US at a lower intensity could be a reasonable treatment method for both decreasing the toxicity of US and enhancing its antitumor effects. It is known that photosensitizers used for PDT can also be used for SDT. Among these photosensitizers, 5-ALA is a natural porphyrin precursor that is already being used in photodynamic diagnosis, and its safety has been confirmed. ${ }^{2}$ Recently, the effect of SDT combined with 5-ALA has been widely in- 
A

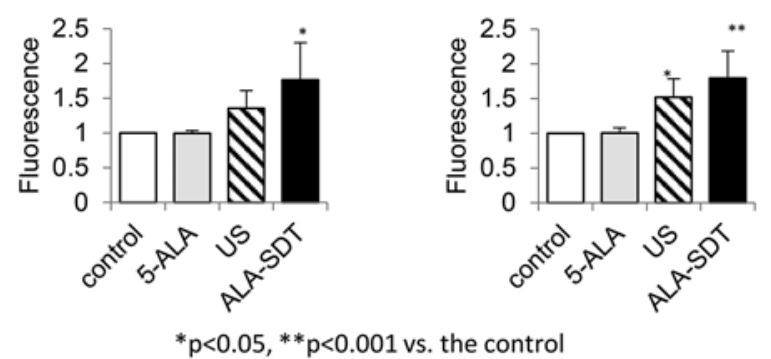

B
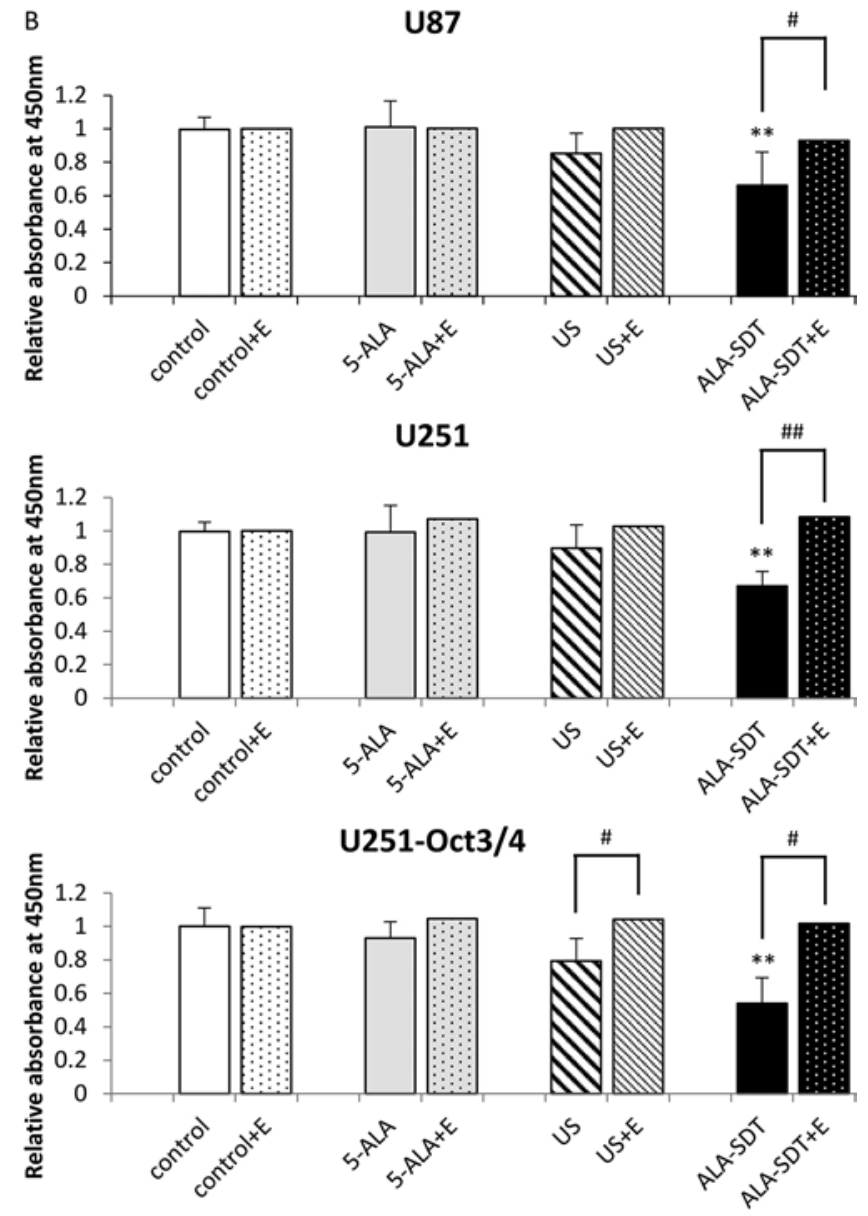

${ }^{*} \mathrm{p}<0.05$ vs. the control $\quad \# \mathrm{p}<0.05$ vs. ALA-SDT

${ }^{* *} \mathrm{p}<0.01$ vs. the control \#\#p<0.01 vs. ALA-SDT

FIG. 5. Bar graphs showing measurement of ROS in SDT and the effects of inhibition of ROS generation on SDT cytotoxic activity. A: The amount of intracellular ROS generated following treatment of glioma cells with 5-ALA or US alone or with 5-ALA-SDT was evaluated by measuring the fluorescence intensity of DCFH-DA within the glioma cells following treatment. The levels of ROS were significantly elevated following treatment of U251 cells with US alone, and also following treatment of both U87 and U251 cells with 5-ALA-SDT compared with the control. The 5-ALA alone did not generate any amount of ROS. Values are expressed as the mean $\pm S D$. B: Effect of inhibition of intracellular ROS generation by US and 5-ALA-SDT with the radical scavenger edaravone (E). The level of ROS was evaluated as for $A$. Edaravone completely eliminated the cytotoxic effects of US alone and of 5-ALASDT in all glioma cells. vestigated in a variety of tumor cells, and its induction of an apoptotic response has indicated that it can contribute to cell death. . $^{70}$

In the current in vitro study, we explored whether 5-ALA-SDT performed using US with a relatively high intensity of $2 \mathrm{~W} / \mathrm{cm}^{2}$ can induce apoptotic cell death not only in glioma cells but also in GSL cells. Flow cytometric analysis demonstrated that even US alone increased the apoptotic cell population, but that 5-ALA-SDT induced a much higher level of apoptosis in all glioma cells than did US alone. In a supplementary study of the flow cytometry performed using the Annexin V-FITC/7-aminoactinomycin D kit, enabling us to measure each cell population of the early apoptosis or necrosis, we found that both 5-ALASDT and US alone enhanced apoptotic cell death, with an increase in necrosis in glioma cells, but that 5-ALA-SDT elevated the apoptotic population much more highly than US alone (unpublished data). These results suggest that apoptosis is likely to be responsible for the cytotoxicity induced by both US and 5-ALA-SDT, and that, compared with US alone, the combination of 5-ALA and US may enhance the apoptotic pathway more highly in these glioma cells. The TUNEL staining demonstrated more prominent DNA fragmentation in both glioma and GSL cells following treatment with 5-ALA-SDT than we observed in the treatment with US alone. This finding may support the concept that the ability of 5-ALA-SDT to induce apoptosis in both nonstem glioma and GSL cells is much greater than that of US alone.

\section{Optimum Dose of 5-ALA for Enabling the Antitumor Activity Induced by 5-ALA-SDT}

The intensity of the cytotoxic effects of 5-ALA-SDT did not differ among glioma cell lines and GSL cells. Cancer stem cells often increase the expression of the ATPbinding cassette transporter $\mathrm{G} 2$ (ABCG2) gene that functions as a drug efflux pump and regulates the intracellular concentration of various drugs, including porphyrins, in cancer cells. ${ }^{21} \mathrm{Xu}$ and colleagues reported that SDT with Photofrin was less effective in killing GSL cells due to the overexpression of $A B C G 2$ in the GSL cells, resulting in a high efflux of Photofrin to the outside of the cells. ${ }^{25,26} \mathrm{We}$ have previously demonstrated that U251 ${ }^{\text {oct- } 3 / 4}$ GSL cells highly express the $A B C G 2$ gene and the ABCG2 protein, as do U87 glioma cells, whereas U251 glioma cells expressed them at a very low level. ${ }^{6}$ A dose-response study of 5-ALA-derived protoporphyrin IX (PpIX) production showed that the expression level of $A B C G 2$ might influence the intra- and extracellular concentrations of PpIX in these cell lines. The U87 and U251 ${ }^{\text {Oct-3/4 }}$ cells showed a dose-dependent increase of both intra- and extracellular concentrations of PpIX with the increasing dose of 5-ALA, and showed maximum values at a 5-ALA dose of $1 \mathrm{mM}$, whereas U251 glioma cells similarly increased the intracellular PpIX concentration, but did not show an increase in extracellular PpIX until the 5-ALA concentration was greater than $1 \mathrm{mM}$.

We did not examine what dose of 5-ALA can induce cytotoxic effects in glioma cells; however, Shimamura et al. reported that 5-ALA showed strong cytotoxicity at a concentration of not less than $3 \mathrm{mM}$ in mouse mammary 

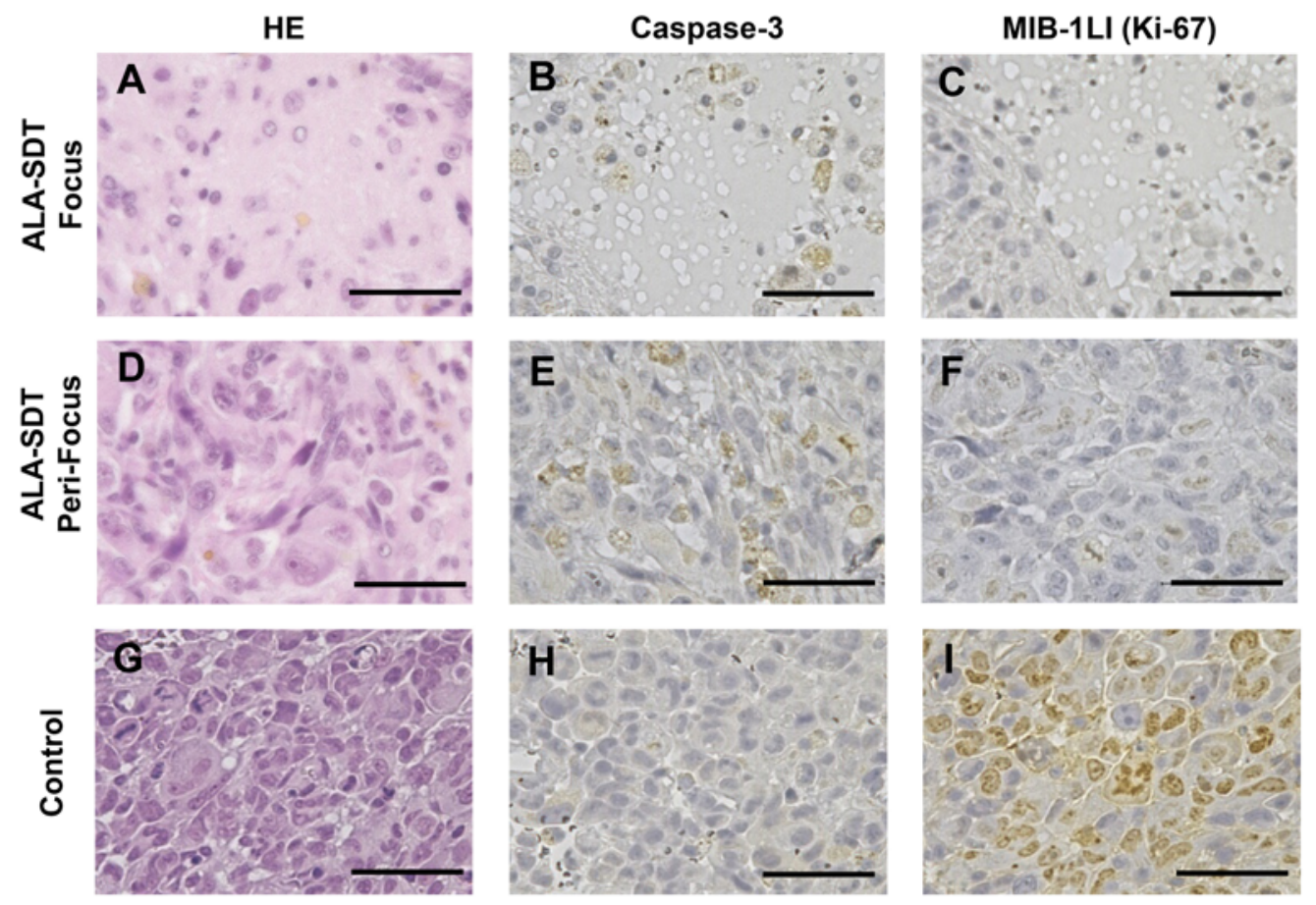

Bar: $50 \mu \mathrm{m}$
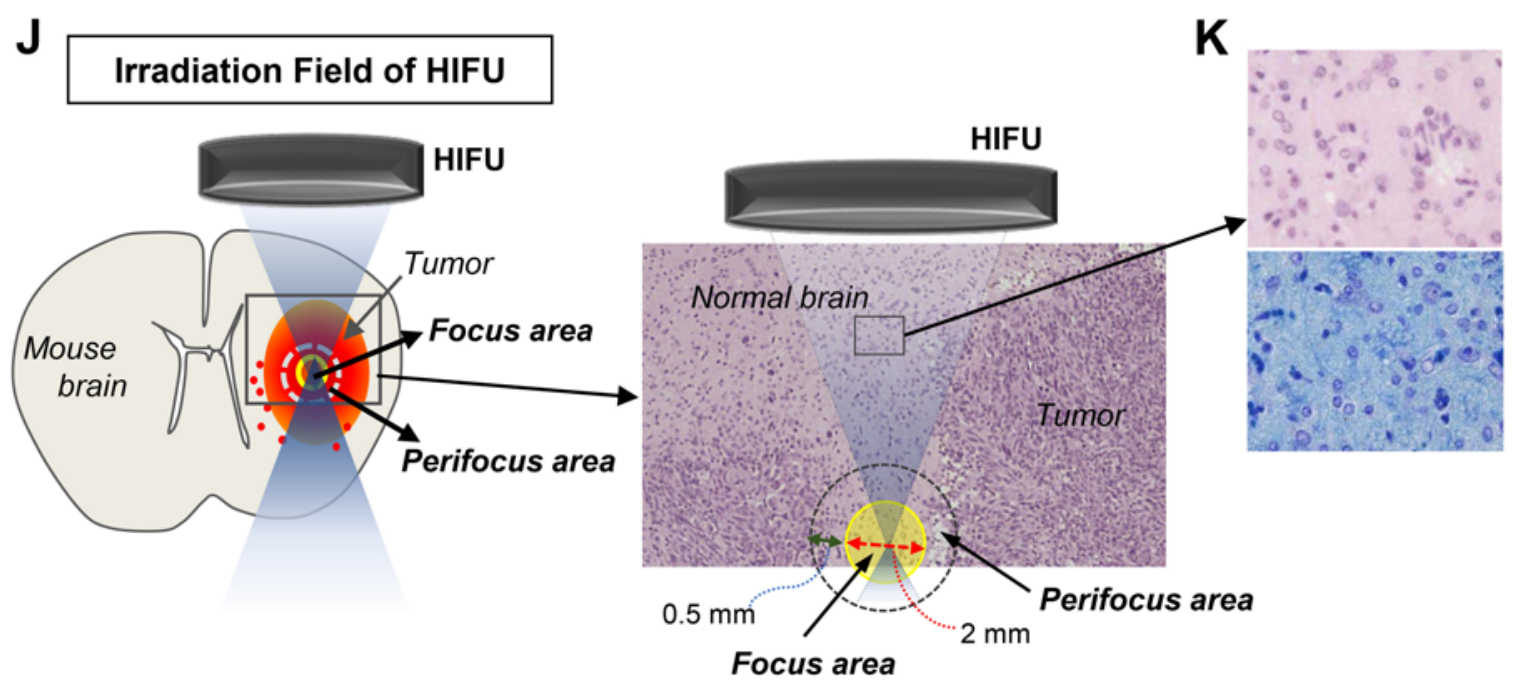

FIG. 6. Photomicrographs showing histopathological samples of the tumors in mouse brains after 5-ALA-SDT with HIFU and an illustration showing the 2 areas of HIFU irradiation. The brain tumors of glioma-bearing mice treated with 5-ALA-SDT and HIFU were evaluated by analyzing histological features in the area at the focus of HIFU irradiation (A-C), and in the perifocus area (within $0.5 \mathrm{~mm}$ around the focus, D-F). These 2 areas were defined as shown in the illustration described below. Histological features of control glioma-bearing mice $(\mathbf{G}-\mathbf{I})$ are also shown. In the control, the tumor grown in the mouse brain consisted of a high density of tumor cells with many atypical nuclei and mitosis (G). Many cells were positively stained for Ki-67 (I). In the focused area of the tumor treated with 5-ALA-SDT, the central region of the tumor tissue showed necrosis $(A)$, and tumor cells around the necrotic area were positively stained for caspase-3 (B). There were few Ki-67-positive cells (C). In the perifocused area of the tumor treated with 5-ALA-SDT (D), the tumor cell density was decreased versus control, many caspase-3-positive cells were observed $(E)$, and no tumor cells stained positively for Ki-67 (F). J: Illustration of the focus and perifocus areas in the irradiation of HIFU to the tumor in the mouse brain (left) and the corresponding photomicrograph of brain histological sample showing these 2 areas in the tumor grown in the mouse brain after irradiation with HIFU (right). The focus area is a rounded shape with a diameter of approximately $2 \mathrm{~mm}$ with the highest intensity of FUS. The perifocus area is within $0.5 \mathrm{~mm}$ around the focus area. K: Histological samples of the brain tissue within the irradiation field of HIFU showing no injury to cellular components and normal cell architecture (upper panel, $\mathrm{H}$ \& E; lower panel, Klüver-Barrera stain). MIB-1LI = MIB-1 labeling index. 

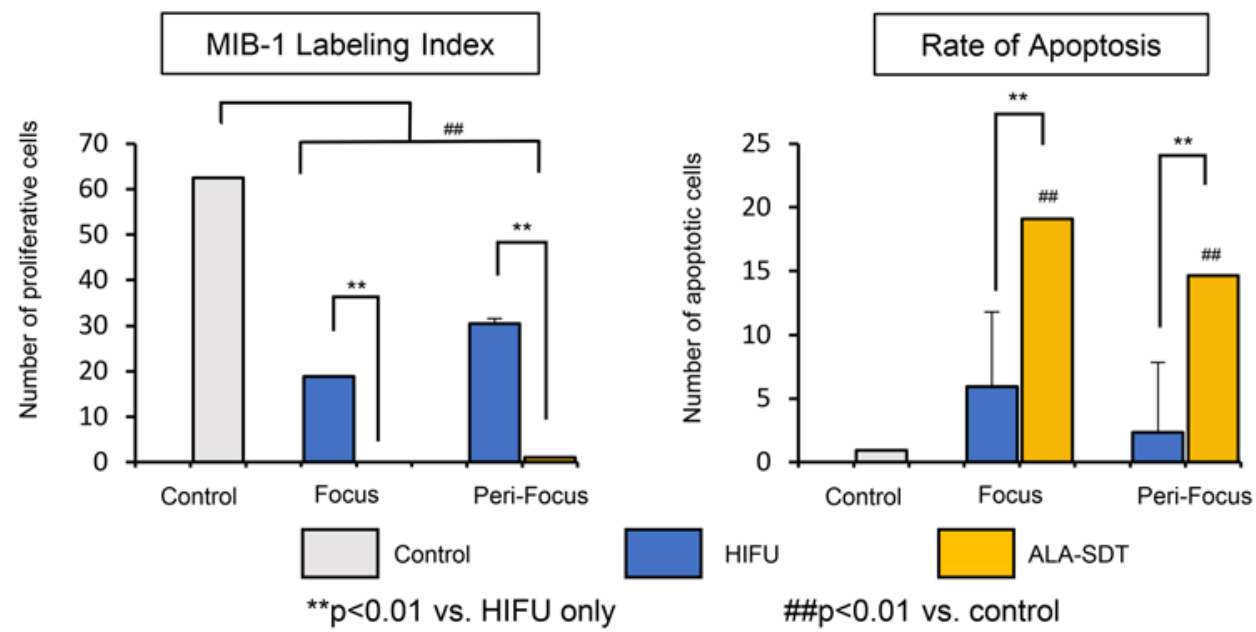

FIG. 7. Bar graphs showing quantitative analysis of the MIB-1 index and apoptotic tumor cells after 5-ALA-SDT with HIFU. The focus or perifocus areas of brain tumors of glioma-bearing mice that were treated with HIFU or with 5-ALA-SDT were analyzed for the MIB-1 staining index (left) and for apoptotic rates (right). The MIB-1 staining index was calculated based on the numbers of proliferating cells in tumor tissue that were positively stained for Ki-67 in immunohistochemistry. Apoptotic rates were calculated by evaluation of the number of caspase-3-positive cells in immunohistochemistry.

tumor cells. ${ }^{16}$ Based on these data, we determined that the optimal concentration of 5-ALA in the present in vitro studies was $1 \mathrm{mM}$. At this dose, the intracellular concentration of PpIX was almost the same among these 3 cell lines, although the extracellular concentration was different. The present study, which showed that there was no significant difference in the intensity of the cytotoxicity of 5-ALA-SDT among these cells, may indicate that the levels of intracellular PpIX are primarily responsible for the cytotoxic effect of 5-ALA-SDT. These results may indicate that if an appropriate dose of 5-ALA is used to ensure a certain concentration of intracellular PpIX, then the antitumor function of 5-ALA-SDT can operate effectively even in glioma cells that show a high efflux for drugs.

\section{Role of ROS Generated by 5-ALA-SDT in the Treatment-Related Cytotoxicity}

Regarding mechanisms of the antitumor activity induced by SDT, it has been suggested that intracellular ROS, such as superoxide radicals, singlet oxygen, and hydrogen peroxide generated by SDT, are responsible for apoptotic cell death, resulting in cytotoxicity against tumor cells. ${ }^{11}$ We measured ROS in glioma cells treated with US alone or US combined with 5-ALA. Significant amounts of ROS were generated by US alone. The 5-ALA-SDT generated much higher amounts of ROS than US alone, although there was no significant difference between the 2 modes of treatment. Inhibition of the generation of ROS with the radical scavenger, edaravone, almost completely eliminated the cytotoxic effects of both 5-ALA-SDT and US alone. These results may suggest that ROS generated by chemical reactions through SDT are likely to be a cause of apoptotic cell death, resulting in antitumor activity. However, it is also possible that other factors, including direct induction of necrosis due to the thermal effect of the treatment, may participate in the cell death promoted by 5-ALA-SDT.

\section{Antitumor Effects in the Glioma-Bearing Mice by SDT Performed Using HIFU}

In the in vivo study, taking into consideration the potential clinical application, we used a HIFU unit with a transducer frequency of $2.2 \mathrm{MHz}$ and an acoustic intensity of $0.5 \mathrm{~kW} / \mathrm{cm}^{2}$ for US irradiation so that the US wave would penetrate through the mouse skull and focus at a depth of $5 \mathrm{~mm}$ in the mouse brain. The HIFU irradiation was performed once a week for 3 weeks to control the rapid growth of residual tumors, because the focused area of HIFU was not large enough to span the entire tumor mass for a single treatment. Preliminary experiments indicated that the residual tumor continued to grow and expand around the lesion within 4-7 days of the first 5-ALA-SDT treatment. Song et al. also reported that the tumors that remain after SDT inevitably grow within 14 days and that, therefore, multiple SDT treatments may be required to fully control the growth of the lesions. ${ }^{17}$ We demonstrated that the mice treated with 5-ALA-SDT by using HIFU survived much longer than either the untreated mice (control) or the mice treated with HIFU alone. Histological examination after the death of the untreated mice disclosed that the cause of death was due to the proliferating tumor. All mice treated with 5-ALASDT also died of growing tumors at a later period. These results suggest that more irradiation performed using HIFU combined with 5-ALA to the untreated area may further prolong survival time without impairing brain functions, because the brain tissues around the tumor where irradiation performed using HIFU passed through were histologically intact despite repeated SDT.

As the tissue temperature at an irradiation focus increases with HIFU irradiation, adverse effects, such as intratumoral bleeding, may occur. On the other hand, the high temperature may be an advantage for tumor cell killing because 5-ALA can enhance heat-induced cell death of cancer cell lines by acting as a thermosensitizer. ${ }^{1}$ For clinical application, the influence of increased temperature 

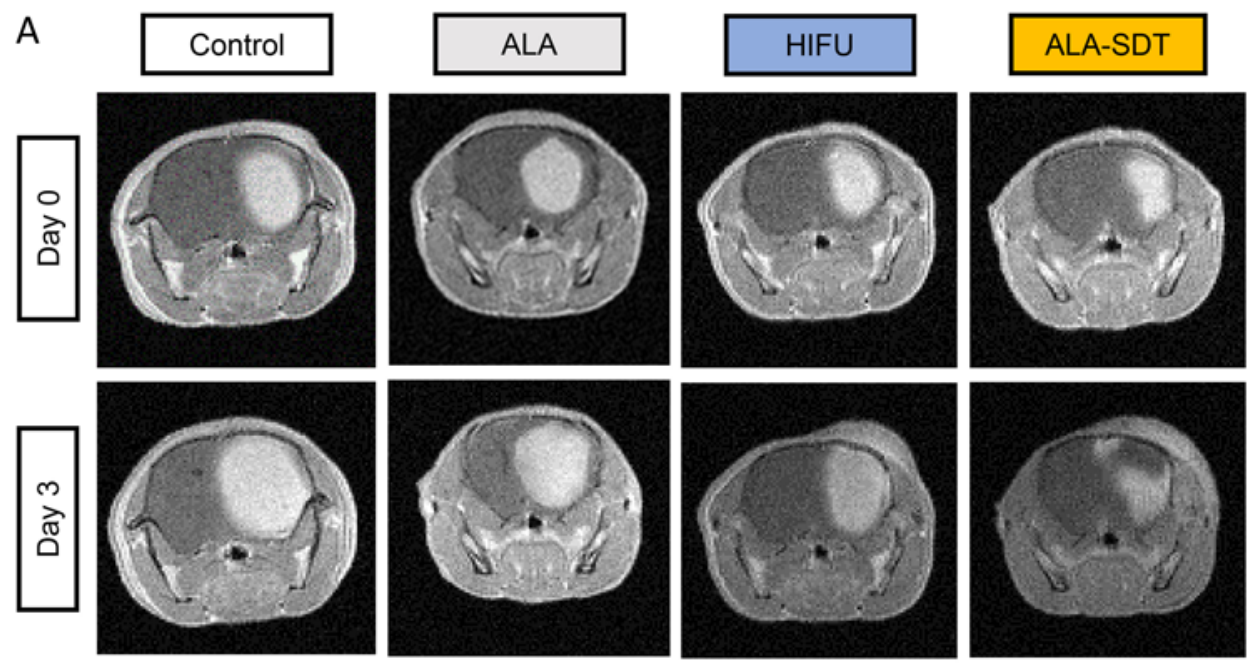

T1Gd

B

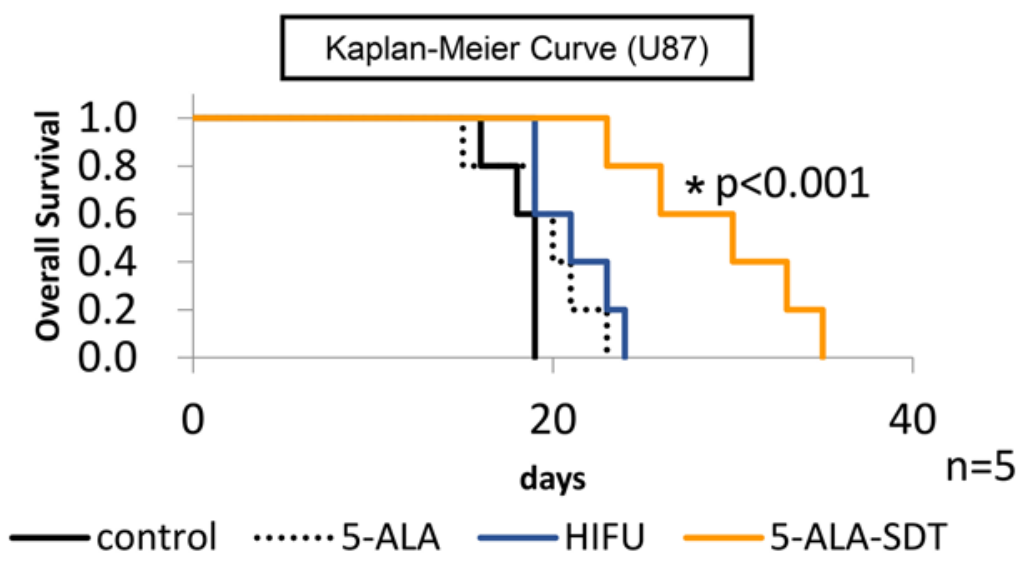

FIG. 8. Analysis of brain tumors on MRI studies obtained pre- and post-SDT, and survival curves of the mice. A: The MR images obtained on day 0 (before SDT) and on day 3 after SDT with HIFU, without HIFU (control), or with 5-ALA (i.e., 5-ALA-SDT), and after administration of 5-ALA alone. In the rightmost column, the MRI on day 3 after 5-ALA-SDT demonstrated a partial loss of Gd enhancement, showing death of the tumor cells. The MR images in the leftmost column (untreated tumors; control) and MR images in the second column from the left (tumors with 5-ALA alone) showed rapidly growing tumors during the period from day 0 to day 3 . In the second column from the right, HIFU alone was ineffective in inhibiting the tumor growth and the MR images showed an apparent increase in the tumor mass 3 days after the SDT. B: Kaplan-Meier curves of overall survival in tumor-bearing mice treated with HIFU alone, with 5-ALA-SDT with or without HIFU, or not treated (control). The tumor-bearing mice treated with 5-ALA-SDT with HIFU survived for a significantly longer time than did those treated with HIFU alone, those treated with 5-ALA alone, or those that were not treated (control). ${ }^{*} p<0.001$ versus control or HIFU alone.

in SDT on tumor growth and normal brain tissues needs to be further studied.

\section{Pathological Changes in the Transplanted Tumor Tissues by 5-ALA-SDT Performed With HIFU}

In an in vivo SDT study, it is very important to accurately adjust the focus point of HIFU to the targeted area within the tumor. We adjusted the position of the center of the HIFU transducer to the tumor injection site by measuring the scale of the stereotactic apparatus. In histopathological analysis, approximately $5 \%-15 \%$ of tumors in the perifocused area of HIFU irradiation were positively stained for caspase-3. Because these perifocused areas were included in the pathway of HIFU irradiation, these data suggest that apoptotic change could be induced in tumor cells in the areas that received less irradiation due to the decreased intensity of the HIFU. The cause of this apoptosis may have been that glioma cells in which PpIX had accumulated initiated a reaction cascade for cellular apoptosis even with a lower intensity of HIFU. This hypothetical mechanism may explain why, even after a single treatment of 5-ALASDT performed using HIFU, the remaining tumor did not grow as rapidly as not only the untreated tumor in mouse brain but also the tumor treated with HIFU alone, as seen on MRI (Fig. 8A). These results suggest that it may be possible to specifically kill the infiltrating tumor cells at the invasive front of malignant glioma that have accumulated PpIX by promoting apoptosis induction with 5-ALA-SDT performed using HIFU. 


\section{Future Prospects of 5-ALA-SDT With HIFU}

The combination of 5-ALA-SDT with HIFU has the possibility to be a much more effective therapy for malignant gliomas, not only in the initial treatment but also at tumor progression or recurrence. The treatment is tumor specific based on the selective accumulation of the 5-ALA-derived porphyrin molecule in malignant glioma cells, including GSL cells, and can be performed without craniotomy and repeatedly, unlike radiation therapy. In addition, ultrasonic irradiation by SDT can penetrate much deeper into brain tissues than light irradiation by PDT, resulting in much stronger antitumor effects on infiltrating tumors. It is also interesting that 5-ALA-SDT with HIFU was shown to be effective in killing GSL cells that are likely a main cause for tumor progression and local recurrence after tumor resection.

However, to apply SDT to human malignant gliomas, several problems remain to be resolved. These problems include determination of the optimum amount of actual accumulation of 5-ALA-derived PpIX in glioma cells, particularly in the infiltrating cells; determination of the influence of extracellular PpIX on tumors and normal brain tissues; and determination of more detailed molecular mechanisms underlying the antitumor activity. There is also the possibility of tissue injury by ROS generated by 5-ALA-SDT. Of these problems, the most important is determination of the optimum conditions of HIFU that will effectively kill the tumors without injury to normal brain tissues-in particular, to control the infiltrating tumor cells at the invasion front through apoptotic cell death induced by the relatively lower intensity of HIFU irradiation in the near focus region (i.e., farther away than the perifocus). To clarify a substantial cytotoxic effect of 5-ALA-SDT with HIFU on infiltrating tumor cells around the tumor that cause a poor prognosis in patients with malignant glioma, we are proceeding to investigate the cytotoxic effect of 5-ALA-SDT with HIFU, in particular on such infiltrating tumor cells, by using an in vivo optical imaging system.

\section{Conclusions}

The use of 5-ALA-SDT could effectively promote cell death through apoptosis in not only glioma cell lines but also GSL cells. Regarding the underlying mechanism, ROS generated by 5-ALA-SDT may have a significant role in promoting the apoptotic cascade. Treatment with 5-ALA-SDT using HIFU in glioma-transplanted mice had a marked antitumor effect, whereas the surrounding brain tissues remained normal, resulting in longer survival of the mice. Histologically, 5-ALA-SDT performed using HIFU produced mainly tumor necrosis in the focused area of HIFU and induced apoptotic changes in the tumor cells in the perifocused area under the irradiated field of HIFU. By determining the optimum intensity of HIFU combined with 5-ALA that can induce effective apoptosis of glioma cells, it is expected that SDT using HIFU combined with the sonosensitizer 5-ALA may be a potent and less invasive therapy for malignant gliomas in the future.

\section{Acknowledgments}

We thank Drs. Yoichi Negishi, Yoko Takahashi (Tokyo Uni- versity of Pharmacy and Life Sciences), and Toru Kondo (Division of Stem Cell Biology, Institute for Genetic Medicine, Hokkaido University) for their technical suggestions, and Dr. Kenji Kameda (Advanced Research Support Center, Ehime University) for his technical assistance with flow cytometric analysis.

\section{References}

1. Chibazakura T, Toriyabe Y, Fujii H, Takahashi K, Kawakami M, Kuwamura H, et al: 5-Aminolevulinic acid enhances cell death under thermal stress in certain cancer cell lines. Biosci Biotechnol Biochem 79:422-431, 2015

2. Colditz MJ, van Leyen K, Jeffree RL: Aminolevulinic acid (ALA)-protoporphyrin IX fluorescence guided tumour resection. Part 2: theoretical, biochemical and practical aspects. J Clin Neurosci 19:1611-1616, 2012

3. Committee for the Update of the Guide for the Care and Use of Laboratory Animals: Guide for the Care and Use of Laboratory Animals, ed 8. Washington, DC: National Research Council, 2011 (https://grants.nih.gov/grants/olaw/ guide-for-the-care-and-use-of-laboratory-animals.pdf) [Accessed December 29, 2017]

4. Dobrakowski PP, Machowska-Majchrzak AK, Labuz-Roszak B, Majchrzak KG, Kluczewska E: MR-guided focused ultrasound: a new generation treatment of Parkinson's disease, essential tremor and neuropathic pain. Interv Neuroradiol 20:275-282, 2014

5. Feril LB Jr, Kondo T: Biological effects of low intensity ultrasound: the mechanism involved, and its implications on therapy and on biosafety of ultrasound. J Radiat Res (Tokyo) 45:479-489, 2004

6. Hosokawa Y, Takahashi H, Inoue A, Kawabe Y, Funahashi Y, Kameda K, et al: Oct-3/4 modulates the drug-resistant phenotype of glioblastoma cells through expression of ATP binding cassette transporter G2. Biochim Biophys Acta 1850:11971205,2015

7. Hu Z, Fan H, Lv G, Zhou Q, Yang B, Zheng J, et al: 5-Aminolevulinic acid-mediated sonodynamic therapy induces antitumor effects in malignant melanoma via p53-miR-34a-Sirt1 axis. J Dermatol Sci 79:155-162, 2015

8. Jeong EJ, Seo SJ, Ahn YJ, Choi KH, Kim KH, Kim JK: Sonodynamically induced antitumor effects of 5-aminolevulinic acid and fractionated ultrasound irradiation in an orthotopic rat glioma model. Ultrasound Med Biol 38:2143-2150, 2012

9. Kobayashi K, Takahashi H, Inoue A, Harada H, Toshimori S, Kobayashi Y, et al: Oct-3/4 promotes migration and invasion of glioblastoma cells. J Cell Biochem 113:508-517, 2012

10. Li Y, Zhou Q, Hu Z, Yang B, Li Q, Wang J, et al: 5-aminolevulinic acid-based sonodynamic therapy induces the apoptosis of osteosarcoma in mice. PLoS One 10:e0132074, 2015

11. Miyoshi N, Misík V, Riesz P: Sonodynamic toxicity of gallium-porphyrin analogue ATX-70 in human leukemia cells. Radiat Res 148:43-47, 1997

12. Muragaki Y, Akimoto J, Maruyama T, Iseki H, Ikuta S, Nitta $\mathrm{M}$, et al: Phase II clinical study on intraoperative photodynamic therapy with talaporfin sodium and semiconductor laser in patients with malignant brain tumors. J Neurosurg 119:845-852, 2013

13. Nonaka M, Yamamoto M, Yoshino S, Umemura S, Sasaki K, Fukushima T: Sonodynamic therapy consisting of focused ultrasound and a photosensitizer causes a selective antitumor effect in a rat intracranial glioma model. Anticancer Res 29:943-950, 2009

14. Ohmura T, Fukushima T, Shibaguchi H, Yoshizawa S, Inoue $\mathrm{T}$, Kuroki M, et al: Sonodynamic therapy with 5-aminolevulinic acid and focused ultrasound for deep-seated intracranial glioma in rat. Anticancer Res 31:2527-2533, 2011

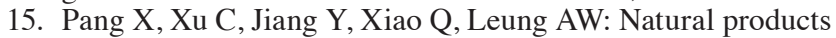
in the discovery of novel sonosensitizers. Pharmacol Ther 162:144-151, 2016 
16. Shimamura Y, Tamatani D, Kuniyasu S, Mizuki Y, Suzuki T, Katsura H, et al: 5-aminolevulinic acid enhances ultrasoundmediated antitumor activity via mitochondrial oxidative damage in breast cancer. Anticancer Res 36:3607-3612, 2016

17. Song D, Yue W, Li Z, Li J, Zhao J, Zhang N: Study of the mechanism of sonodynamic therapy in a rat glioma model. Onco Targets Ther 7:1801-1810, 2014

18. Stummer W, Pichlmeier U, Meinel T, Wiestler OD, Zanella F, Reulen HJ: Fluorescence-guided surgery with 5-aminolevulinic acid for resection of malignant glioma: a randomised controlled multicentre phase III trial. Lancet Oncol 7:392401, 2006

19. Stupp R, Mason WP, van den Bent MJ, Weller M, Fisher B, Taphoorn MJB, et al: Radiotherapy plus concomitant and adjuvant temozolomide for glioblastoma. N Engl J Med 352:987-996, 2005

20. Suffredini G, Levy LM: MR-guided, focused ultrasound: applications to essential tremor and other neurologic conditions. AJNR Am J Neuroradiol 35:829-831, 2014

21. Szakács G, Paterson JK, Ludwig JA, Booth-Genthe C, Gottesman MM: Targeting multidrug resistance in cancer. Nat Rev Drug Discov 5:219-234, 2006

22. Takahashi H, Inoue A, Kawabe Y, Hosokawa Y, Iwata S, Sugimoto K, et al: Oct-3/4 promotes tumor angiogenesis through VEGF production in glioblastoma. Brain Tumor Pathol 32:31-40, 2015

23. Tominaga H, Ishiyama M, Ohseto F, Sasamoto K, Hamamoto T, Suzuki K, et al: A water-soluble tetrazolium salt useful for colorimetric cell viability assay. Anal Commun 36:47-50, 1999

24. Umemura S, Yumita N, Nishigaki R, Umemura K: Mechanism of cell damage by ultrasound in combination with hematoporphyrin. Jpn J Cancer Res 81:962-966, 1990

25. Xu ZY, Li XQ, Chen S, Cheng Y, Deng JM, Wang ZG: Glioma stem-like cells are less susceptible than glioma cells to sonodynamic therapy with Photofrin. Technol Cancer Res Treat 11:615-623, 2012
26. Xu ZY, Wang K, Li XQ, Chen S, Deng JM, Cheng Y, et al: The ABCG2 transporter is a key molecular determinant of the efficacy of sonodynamic therapy with Photofrin in glioma stem-like cells. Ultrasonics 53:232-238, 2013

\section{Disclosures}

The authors report no conflict of interest concerning the materials or methods used in this study or the findings specified in this paper.

\section{Author Contributions}

Conception and design: Suehiro, Ohnishi. Acquisition of data: Suehiro, Yamashita, Inoue, Nishikawa, Tanaka. Analysis and interpretation of data: Suehiro, Ohnishi, Yamashita, Ohue. Drafting the article: Suehiro. Critically revising the article: Yamashita, Ohue, Kunieda. Reviewed submitted version of manuscript: Suehiro, Ohnishi. Approved the final version of the manuscript on behalf of all authors: Suehiro. Statistical analysis: Suehiro, Ohue. Administrative/technical/material support: Suehiro, Ohnishi, Kohno, Inoue, Nishikawa, Ohue. Study supervision: Ohnishi, Tanaka, Kunieda.

\section{Supplemental Information}

Online-Only Content

Supplemental material is available with the online version of the article.

Supplemental Figures. https://thejns.org/doi/suppl/10.3171/ 2017.6.JNS162398.

\section{Correspondence}

Satoshi Suehiro: Ehime University Graduate School of Medicine, Toon, Ehime, Japan. satoshis@m.ehime-u.ac.jp. 